\title{
Influence of Gender on Teachers' Self-Efficacy in Secondary Schools of Kisumu County, Kenya
}

\author{
Sylvester J. O. Odanga \\ PhD Student, Jaramogi Oginga Odinga University of Science and Technology
}

\author{
Dr. Pamela A. Raburu
}

Head of Department of Psychology, Jaramogi Oginga Odinga University of Science and Technology

*Dr. Peter J.O. Aloka

Department of Psychology, Jaramogi Oginga Odinga University of Science and Technology P.O. BOX 210, Bondo, 40601, Kenya; jairopeteraloka@yahoo.com

Doi:10.5901/ajis.2015.v4n3p189

\begin{abstract}
The study investigated the influence of gender on teachers' self-efficacy in public secondary schools of Kisumu County, Kenya. Bandura's (1989) Social Cognitive Theory guided the study. The study employed the mixed methods approach within which a concurrent triangulation design was used. The target population was 1790 teachers in 143 public secondary schools from which a sample size of 327 teachers was drawn using stratified random sampling. Questionnaires and interview schedule were used to collect data. Piloting helped to clarify the test items, determine construct validity $(r=0.564$ for items expected to have similar responses and $r=-0.325$ for items expected to have different responses) and establish internal reliability (Cronbach's a $=0.9976$ ). Two experts in Educational Psychology established face validity of the data collection instruments. Qualitative data was transcribed verbatim and analyzed thematically while quantitative data was analyzed using descriptive statistics and Multivariate Analysis of Variance (MANOVA). The MANOVA results revealed that there was no statistically significant influence of gender on teachers' self-efficacy, but the qualitative results revealed that gender had an influence on self-efficacy of teachers in co-educational and Boys' schools. The study recommended that teacher counsellors be empowered to counsel female teachers on the challenges of teaching in co-educational and Boys' schools.
\end{abstract}

Keywords: self-efficacy; teachers; gender; secondary school; students.

\section{Introduction}

Self-efficacy is the personal belief of possessing the ability to perform professional tasks with mastery (Page, Pendergraft $\&$ Wilson, 2014). Teachers' self-efficacy is the teachers' confidence in their ability to promote students' learning and it determines levels of effectiveness, innovativeness and persistence among teachers (Protheroe, 2008; Klassen \& Chiu, 2010). Furthermore, Protheroe (2008) added that teachers with a stronger sense of efficacy were good in planning and organizing their work, more open to new ideas and innovative, more persistent and resilient and less critical of students. Additionally, Adu, Tadu and Eze (2012) reiterate that teachers' self-efficacy is important because it has a positive relationship between teachers' self-efficacy and students' academic performance.

DeJaeghere, Williams and Kyeyune (2009) study in sub-Saharan Africa found that head teachers had low selfefficacies in leadership, management, instructional supervision and community relations. Butucha (2014) in Ethiopia found that gender had significant influence on teachers' self-efficacy. On the other hand, in Tanzania, Jumanne (2012) study found that the teachers had average levels self-efficacy towards teaching of science process skills. In addition, Ngonyani and Werf (2013) in Tanzania found that classroom variables affected teachers' self-efficacy on inclusive education. Aurah and McConnell (2014) and Kinyua and Oboko (2013) studies both found that gender had a statistically significant influence on teachers' self-efficacy. In Kisumu County of Kenya, Obura and Ajowi (2012) highlighted the importance of self-efficacy in Kisumu Municipality when the study found that self-efficacy has an influence on students' career aspirations and performance in examinations. In addition, Odongo (2011) and Oginga, Muola and Mwania (2014) added that teachers' self-efficacies in special needs and HIV\&AIDS education were low and that the low teachers' self- 
efficacy negatively affected curriculum implementation by teachers. The studies by Obura and Ajowi (2012), Odongo (2011) and Oginga et al. (2014), therefore, were specific to some aspects of teaching and did not consider teachers' selfefficacy in all aspects of teaching. Furthermore, the studies were conducted only in certain parts of Kisumu County and did not investigate the influence of gender on teachers' self-efficacy. Therefore, the current study sought to investigate the influence of gender on teachers' self-efficacy in public secondary schools in of Kisumu County, Kenya.

\section{Theoretical Framework and Literature Review}

\subsection{Theoretical Framework}

The study was informed by Bandura's (1989) social cognitive theory, which adopts an agentic perspective where people intentionally influence their functioning through self-directed goal tendency to achieve self-development (Bandura, 2001; 2005). The social cognitive theory posits a triadic understanding of human functioning as a reciprocal determinism among personal factors such as gender, behavior such as teaching and environment such as a school setting. Self-efficacy is a person's beliefs about the capabilities to perform a behavior successfully (Bandura, 1989; Bandura, 1994; BUSPH, 2013). Teachers' self-efficacy is the teachers' beliefs in their personal capability to motivate and promote learning affect the type of learning environments they create and the level of academic progress their students achieve (Bandura, 1993).

The work of Tschannen-Moran and Hoy (2001) on teachers' self-efficacy identified three domains in the construct of teachers' self-efficacy, which are, teacher self-efficacy in instructional strategies, student engagement and classroom management that are captured in the Teacher Self-Efficacy Scale. Instructional strategies are techniques to make students independent, strategic learners through motivation, focused attention, organization of information, monitoring and assessment of learning (Alberta Learning, 2002). Teacher self-efficacy in instructional strategies means the teacher's self-beliefs in their capability to use innovative techniques that promote learning among students. Teacher self-efficacy in student engagement refers to the teacher's self-beliefs about their capability to motivate students to learn (Moalosi, 2012). Hence, teachers' self-efficacy in classroom management means teachers' self-beliefs in their capability to create an environment that supports and facilitates both academic and social-emotional learning using appropriate instructional procedures (Oliver, Wehby \& Daniel, 2011). Therefore, this investigation into influence of demographic variables on teachers' self-efficacy included these domains of teacher self-efficacy. Bandura's (1989) social cognitive theory, therefore, informed the current study by supplying the construct studied, that is, teachers' self-efficacy and it also provided the personal factor investigated, that is, gender.

\subsection{Literature Review}

Gender, in the current study, referred to the attitudes, feelings and behaviors associated with a person's biological sex while sex refers to a person's biological status indicated by sex chromosomes and external genitalia (American Psychological Association [APA], 2011). Since self-efficacy involves attitudes, feelings and behaviors of, the concept of gender was deemed more appropriate than sex as a variable for the current study. Therefore, gender was investigated as male and female.

An exploratory study conducted in Albania, Europe by Bilali (2013) found that female and male teachers had similar levels of self-efficacy. The study reported that there was no significant difference in the level of sense of efficacy across gender, that is, both female and male teachers had similar levels of self-efficacy. However, the above reviewed study used student-teachers in a University setting which may be different from the setting of employed teachers engaged in actual classroom teaching. Furthermore, the study was conducted in the European nation of Albania and used only the quantitative approach when a mixed methods approach would have yielded findings with more meaning. Furthermore, Klassen and Chiu (2010) study reported that female teachers had lower classroom management selfefficacy than male teachers and found that female teachers had higher self-efficacy than male teachers did. Similarly, Aktaş, Kurt, Aksu and Ekici (2013) used regression analysis to examine biology teachers' self-efficacy and gender in Turkey. The results of the regression analysis indicated that gender positively and significantly predicted education process self-efficacy perception. Gender accounted for $11.4 \%$ of the total variance in education process self-efficacy perception. However, the study only used volunteering Turkish biology teachers and not Kenyan teachers.

Furthermore, Arslan (2013) study in Turkey indicated that there were significant differences between students' opinions about sources of self-efficacy based on their gender. Consequently, Akram and Ghazanfar (2014) study among students of University of Gujarat, Pakistan, revealed a difference in the level of academic self-efficacy with respect to 
gender with male students showing higher levels of self-efficacy. However, the study was on Pakistani University students and not Kenyan teachers, which the current study focused on.

On the contrary, Senemoglu, Demirel, Yagci and Ustundag (2009) found that the relationship between self-efficacy and gender was not significant in Turkey. However, the study used Turkish elementary school teachers sampled purposively and not Kenyan secondary school teachers sampled randomly. These findings were contrary to those of Mackay and Parkinson (2010) in South Africa, which revealed that males had higher levels of self-efficacy than females. However, the study used South African teacher trainees and not practicing Kenyan teachers.

A study conducted in Nigeria by Okenyi and Enyi (2015) indicated that gender, did not predict ego identity. However, the study was a quantitative approach conducted on Nigerian students' ego identity and not a mixed methods approach study on Kenyan teachers' self-efficacy. Similarly, a study in Ethiopia by Tenaw (2013) indicated that there was no significant difference in the self-efficacy between males and females. The study however was carried out in Ethiopia and not Kenya as was the case in the preent study. In addition, Mohammed, Atagana and Edawoke (2014) in Ethiopia indicated that there was statistically significant difference between male and female students in self-efficacy. Male students showed higher self-efficacy than female students did. However, the study reviewed investigated Ethiopian students and not Kenyan teachers, as was the present study.

A study in Kenya by Ongowo and Hungi (2014) revealed girls had higher self-efficacy score than boys had. In addition, Nanjala (2012) analyzed gender differences on entrepreneurial self-efficacy using small and medium entrepreneurs in Githurai trading centre, Nairobi, Kenya. The findings indicated that men reported significantly higher levels of entrepreneurial self-efficacy than women do. Nevertheless, the study investigated entrepreneurial self-efficacy in Githurai using a purposive sample and not teachers' self-efficacy in Kisumu using stratified random sample. Furthermore, the study analyzed data using descriptive and chi-square analyses, which have lower statistical strength than MANOVA. Moreover, Moturi (2014) in Nyamira County, Kenya, reported no significant difference in self-efficacy due to gender.

According to Tschannen-Moran and Hoy (2001), the Teachers' Self-Efficacy Scale (TSES) measures three domains of teachers' self-efficacy. These are teachers' self-efficacy in classroom management, student engagement and instructional strategies. Consequently, the current study investigated the influence of gender on specific domains of teacher self-efficacy; these were teachers' self-efficacy in classroom management, student engagement and instructional strategies. The first domain of teachers' self-efficacy was teachers' self-efficacy in classroom management. In the US, Ferrara (2013) found that there was a significant difference between male and female teachers in classroom management. Consequently, Martin, Yin and Mayall (2006) investigated the impact of gender on teachers' classroom management styles in the US. Data analysis revealed significant differences between male and female teachers on instruction management where females scored more interventions than males did. However, the study investigated US teachers' management styles and not Kenyan teachers' self-efficacy in classroom management. In addition, Al-Zu'bi (2013) sought to identify classroom management problems among randomly selected students in Jordan. The study findings revealed that the difference in classroom management according to gender was not significant. According to Butucha (2013) in Ethiopia, there are differences in classroom management based on the genders. The study findings revealed that there were significant gender differences in self-efficacy in classroom management with males having higher self-efficacies than females. However, the study was on Ethiopian teachers and not Kenyan teachers as was the case in the current study.

The second domain of teachers' self-efficacy was the influence of gender on teachers' self-efficacy in student engagement. Tison, Bateman and Culver (2011) examined the relationship between gender and student engagement at the post-secondary level in the US. The findings indicated that there was a significant relationship between gender and student engagement with females scoring higher than males did. The third domain in teacher self-efficacy was teachers' self-efficacy in instructional strategies. Aslan (2009) study in Turkey revealed that there is a significant connection between gender and language learning strategies. However, the study investigated instructional strategy of Turkish students using SILL and not Kenyan teachers' self-efficacy in instructional strategies using TSES. This left an outstanding need for an investigation into teachers' self-efficacy in instructional strategies.

\section{Goal of The study}

The goal of the study was to establish the Influence of gender on teachers' self-efficacy in secondary schools of Kisumu County, Kenya. 


\section{Research Methodology}

\subsection{Research Design}

Research design is a plan for research that covers broad assumptions to detailed methods of data collection and analysis (Creswell, 2008). The current study employed a mixed methods approach through concurrent triangulation design. The current study employed the concurrent triangulation design because concurrent triangulation design leads to convergent validation enables the validation by minimizing biases and increases analytic density (Fielding, 2012; Guion, Diehl \& McDonald, 2011; Yeasmin \& Rahman, 2012). Concurrent triangulation design combined quantitative and qualitative methods through use of questionnaire and interview respectively in data collection on teachers' self-efficacy (Guion et al., 2011; Yeasmin \& Rahman, 2012). Concurrent triangulation design involved the use of different methods and sources to ensure the integrity of data or extend inferences drawn from the data through convergence of both the data and the conclusions derived from the data (Ritchie, 2003). The methods involved collecting data using both questionnaire and interview schedule and the respondents were selected stratified random and purposive sampling receptively.

\subsection{Study Participants}

The population of the study was 1790 secondary school teachers in public secondary schools in Kisumu County (TSC, 2014). Out of this, a sample of 327 was used for the quantitative study and 12 were used for the qualitative study.

\subsection{Research Instruments}

The instruments for collecting quantitative data were questionnaire while qualitative data was collected using interview schedule. Demographic information was collected using a profile that included gender, marital status, age, teaching experience and job group status. This study adopted the longer form of the Teacher Self-Efficacy Scale. TschannenMoran and Hoy (2001) developed the TSES to measure teachers' self-efficacy and its sub-constructs. This study used a semi-structured interview schedule because of the focus and freedom and the richness of meaning it accords (McKenzie \& Hannan, 2007; Raburu, 2011). The current study employed semi-structured interview schedule to conduct in-depth interviewing on teacher self-efficacy.

\subsection{Data Collection Procedures}

The researcher obtained a letter authorizing the use of the Teachers' Self-Efficacy Scale from its author, which allowed the use of the instrument for data collection. Thereafter, the researcher obtained a letter from Board of Post-Graduate Studies (BPGS) of Jaramogi Oginga Odinga University of Science and Technology (JOOUST) to take to the National Council for Science, Technology and Innovation (NACOSTI). The researcher then obtained research permit from NACOSTI to collect data. The researcher personally visited the schools, met the principals and informed them of the nature and purpose of the research. Thereafter dates for data collection were set. Finally, on the dates agreed, the researcher visited the concerned schools to collect data from the sampled teachers.

The data collection procedures were systematic, ethical and rigorous to collect quality data. The participants were debriefed before administration of the questionnaires. Debriefing involves explaining in some detail the purposes and procedures of the research (Taylor, Peplau \& Sears, 2006). Thereafter, the respondents were given the consent form to fill before the questionnaire was administered. The quantitative data was collected through self-report questionnaire that consisted of two sections of demographic variables and teacher self-efficacy scale. The researcher administered the questionnaire personally to the respondents and waited as the respondents filled them. Thereafter, the filled questionnaires were screened and then filed. Each questionnaire took between $10-20$ minutes to administer.

Qualitative data was collected through interview schedule and the interviews were audio-recorded using a digital voice recorder. The researcher conducted the interviews, each of which lasted between $25-60$ minutes. The interviews were held at the participants' places of convenience such as work place and homes. The average length of the interviews was 35 minutes where the shortest interview length was 24 minutes and the longest interview length was 50 minutes. 


\subsection{Data Analysis}

The data was analyzed both quantitatively and qualitatively using statistical procedures and thematic analysis respectively. Quantitative data on teachers' self-efficacy was determined by computing the unweighted means of the TSES items. Data was analysis for inferential and descriptive statistics used both Statistical Package for Social Sciences (SPSS) version 22 and Microsoft Excel. The hypotheses were tested at the $95 \%$ level of confidence. The null hypotheses were tested and if the $p$-value obtained was less than 0.05 , then the null hypothesis was rejected. However, if the p-value obtained was greater than 0.05 , then the null hypothesis was accepted. The hypotheses were tested using Multivariate Analysis of Variance (MANOVA). Qualitative data was analyzed using thematic analysis. Thematic analysis is a method for identifying, analyzing and reporting patterns, called themes, within data by organizing and describing the data set in rich detail (Braun \& Clarke, 2006). Interviews from the interviewees were tape-recorded, transcribed, interpreted, themes and sub-themes emerged and coded as in Raburu (2011).

\section{Findings and Discussion}

It was hypothesized that the influence of gender on teachers' self-efficacy would not be significant. Therefore, the current study performed a multivariate analysis on the influence of gender on the domains of teachers' self-efficacy, which were, efficacy in classroom management, student engagement and instructional strategy. Table 1 presents the descriptive statistics for the influence of gender on the domains of teachers' self-efficacy.

Table 1: Descriptive Statistics for Gender on Domains of Teachers' Self-Efficacy

\begin{tabular}{lcccc}
\hline Domain of Teachers' Self-Efficacy & Gender & N & Mean & S.D. \\
\hline Self-Efficacy in Student Engagement & Male & 208 & 33.55 & 2.929 \\
& Female & 119 & 33.97 & 2.785 \\
& Total & 327 & 33.70 & 2.880 \\
Self-Efficacy in Instructional Strategy & Male & 208 & 34.08 & 3.167 \\
& Female & 119 & 34.44 & 2.641 \\
Self-Efficacy in Classroom Management & Total & 327 & 34.21 & 2.988 \\
& Male & 208 & 33.64 & 3.378 \\
& Female & 119 & 34.39 & 3.009 \\
& Total & 327 & 33.91 & 3.263 \\
\hline
\end{tabular}

The descriptive statistics for gender and the domains of teachers' self-efficacy are presented in Table 1. It shows the descriptive statistics of the respondents on gender across the three domains of teachers' self-efficacy in student engagement, instructional strategies and classroom management were $\mathrm{M}=33.70$ and $\mathrm{SD}=2.880, \mathrm{M}=34.21$ and $\mathrm{SD}=$ 2.988 , and $M=33.91$ and $S D=3.263$ respectively.

Inferential statistics was used to ascertain whether gender systematically influenced of teachers' self-efficacy. A multivariate analysis of variance (MANOVA) was conducted on these variables across the groups of male and female teachers. The results are shown in Table 2.

Table 2: Multivariate tests for Gender on Domains of Teachers' Self-Efficacy

\begin{tabular}{|c|c|c|c|c|c|c|c|c|c|}
\hline Influence & Test & Value & $F$ & Hyp df & Error df & Sig & Partial eta ${ }^{2}$ & Noncent. parameter & Observed power \\
\hline \multirow{4}{*}{ Gender } & Pillai's Trace & .014 & 1.561 & 3.000 & 323.000 & .199 & .014 & 4.684 & .410 \\
\hline & Wilk's Lambda & .986 & 1.561 & 3.000 & 323.000 & .199 & .014 & 4.684 & .410 \\
\hline & Hotelling's Trace & .015 & 1.561 & 3.000 & 323.000 & 199 & .014 & 4.684 & .410 \\
\hline & Roy's Largest Root & .015 & 1.561 & 3.000 & 323.000 & .199 & .014 & 4.684 & .410 \\
\hline
\end{tabular}

Computed using alpha $=0.05$

Presented in Table 2 are the results from MANOVA that demonstrated a non-significant multivariate effect for the relationship, Hotelling's $T(3,323)=0.015, p=.199$. Therefore, the multivariate influence of gender on the domains of teachers' self-efficacy as a group was not significantly different between male and female teachers. This finding is similar to Bilali (2013), Moturi (2014), Okeny and Enyi (2015), Senemoglu (2009) and Tenaw (2013) all found that there was no significant difference between males and females on teachers' self-efficacy. However, the finding of the present study 
was contrary to Akram and Ghazanfar (2014), Aktas et al. (2013), Butucha (2013), Kassen and Chiu (2010), Mackay and Parkinson (2010), Mohammed et al. (2014) and Nanjala (2012) who reported that male teachers had higher self-efficacy than female teachers did. The finding of the current study was also contrary to Andersen (2011), Arslan (2013) and Ongowo and Hungi (2014) who reported that female teachers had higher self-efficacy than male teachers did.

Furthermore, univariate test for the effect of gender on each of the domains of teachers' self-efficacy was performed to determine their level of significance. This is shown in Table 3.

Table 3. Between-subjects effects of Gender on Domains of Teachers' Self-Efficacy

\begin{tabular}{llcccc}
\hline Source & Dependent variable & df & F & Sig & Observed Power \\
\hline Gender & Self-efficacy in Student Engagement & 1 & 1.665 & .198 & .251 \\
& Self-efficacy in Instructional Strategy & 1 & 1.100 & .295 & .182 \\
& Self-efficacy in Classroom Management & 1 & 3.952 & .048 & .509 \\
\hline
\end{tabular}

Computed using alpha $=0.05$

Presented in Table 3 are the univariate tests of between-subjects effects of gender on domains of teachers' self-efficacy, that is, teachers' self-efficacy in student engagement, instructional strategies and classroom management. The results demonstrated a significant influence of gender on classroom management, $F(1,325)=3.952, p=0.048$. However, post hoc tests were not performed for gender because the categories of gender were fewer than three groups, as required by post hoc tests. This finding is similar to Butucha (2013), Ferrara (2013) and Martin et al. (2006) who found that there was a significant difference between male and female teachers' self-efficacy in classroom management. However, the finding of the current study was contrary to Al-Zu'bi (2013) who found that the influence of gender in teachers' self-efficacy in classroom management was not significant. On the other hand, the influence of gender on teachers' self-efficacy in instructional strategies, $F(1,325)=1.100, p=0.295$. This finding was contrary to Aslan (2009) and Martin et al. (2006) who reported that the influence of gender on teachers' self-efficacy in instructional strategies was significant. Furthermore, the influence of gender on teachers' self-efficacy in student engagement, $F(1,325)=1.665, p=0.198$ were not significant. This finding was contrary to Tison et al. (2011) who found that there was a significant influence of gender on teachers' self-efficacy in student engagement.

Most of the interview respondents agreed that gender influenced teachers' self-efficacy. They said that self-efficacy was not only different between males and females but also that male teachers had higher self-efficacy than female teachers did. For instance, one teacher respondent reported that: "It is true that gender dictate self-efficacy, especially in our school. This is shown in the fact that, in our school, female teachers rarely teach Form 4 Class where the students make the decision on the best teachers to teach them" (Teacher 2).

The above cited comment meant that female teachers had lower self-efficacy than the male teachers did because of the demands of teaching certain classes such as Form Four.

Another reason given for the lower female teachers' lower self-efficacy was that female teachers felt intimidated by the male students especially in Boys' schools. One teacher respondent captured this when by saying, "We once had a new female teacher who left the school after teaching only one lesson and said she couldn't come back because she felt intimidated by the boys" (Teacher 3 ).

A third reason given by the teacher respondents on why female teachers had lower self-efficacies was that the cultural background had taught men to feel more capable than women and also taught women to feel less capable than men. For example, one teacher respondent said, "This lower self-efficacy of female teachers is because of culturalization that men are better and females are lesser" (Teacher 1).

The finding of the present study that gender influenced teachers' self-efficacy with male teachers having higher self-efficacies was similar to the findings of Akram and Ghazanfar (2014), Butucha (2013), Klassen and Chiu (2010), Mackay and Parkinson (2010), Mohammed et al. (2014) and Nanjala (2012). These previous studies had found significant influence of gender on teachers' self-efficacy in favor of male teachers. the finding of the current study, however, was contrary to the findings of Bilali (2013), Moturi (2014), Okeny and Enyi (2015), Senemoglu (2009) and Tenaw (2013) who found that there was no significant influence of gender on teachers' self-efficacy. The finding of the current study was also contrary to Andersen (2011), Arslan (2013) and Ongowo and Hungi (2014) who had suggested that female teachers had higher self-efficacy than male teachers did.

Furthermore, some respondents felt on the domain of teacher self-efficacy in instructional strategy revealed that male teachers had higher efficacy in instructional strategies than females. One reason given for the perception that females had higher self-efficacy in instructional strategies than males did included less use technology due to lack of 
extra time to learn to use technology. Another reason was that maternal responsibilities such as maternity leave and taking care of children robed the females of the extra time required to prepare innovative instructional strategies. Two teacher respondents reported that: "The male teachers are more aggressive to look for more information especially using technology, while female teachers have too much of their family issues" (Teacher 4). "It has influence in that female teachers have many things that occupy our minds such as being a mother, being pregnant" (Teacher 7).

The finding of the current study, therefore, was that gender influenced teachers' self-efficacy in instructional strategies in favor of the male teachers. This finding agreed with Aslan (2009) and Martin et al. (2006) who reported that the influence of gender on teachers' self-efficacy in instructional strategies was significant. Nonetheless, in student engagement, one teacher said that female teachers were better than male teachers were. The reason given was that the female teachers were more concerned with the emotional lives of the students. Therefore, the female teachers were more likely to notice when a student was not effectively engaged in the leaning process. One other teacher reported that: "But again, in relating with students, females are better than men in terms of taking care of students' emotional and psychological needs. Mostly men they just go to class and that is all" (Teacher 10).

The current study, therefore, found that gender influenced teachers' self-efficacy in student engagement in favor of the female teachers. This finding is in agreement with Tison et al. (2011) who found that there was a significant influence of gender on teachers' self-efficacy in student engagement.

The teacher respondents felt that the influence of gender on teachers' self-efficacy differed across categories of schools. Such that in Boys' and Sub-County schools male teachers had higher self-efficacy in classroom management more than female teachers did. However, in Girls' schools, female teachers had a higher self-efficacy in classroom management more than male teachers did. A teacher respondent reported that: "The male teachers are better in classroom management because they can handle the students physically" (Teacher 9). Another teacher respondent reported that: "Ladies engage students more because men have a soft spot for the girls but the ladies are more firm and therefore are better in classroom management" (Teacher 8).

This finding was similar to Butucha (2013), Ferrara (2013) and Martin et al. (2006) who found that gender had a significant influence on teachers' self-efficacy in classroom management. However, the finding of the current study was contrary to Al-Zu'bi (2013) who found that the influence of gender on teachers' self-efficacy in classroom management was not significant.

Therefore, quantitative analysis indicated that there was no significant difference in teachers' self-efficacy scores for gender. These results suggest that gender does not have an influence on teachers' self-efficacy. On the domains of teachers' self-efficacy, quantitative analysis indicated that there was no significant difference in the scores for male and female conditions for student engagement and instructional strategies. The influence of gender on classroom management, however, was significant. In qualitative analyses, most of the respondents felt that gender affects teachers' self-efficacy. Most teachers felt that male teachers had higher teachers' self-efficacy that female teachers did. However, one teacher said that female teachers had a higher self-efficacy than male teachers had in a girls' school. Furthermore, it was reported that females had higher teacher self-efficacy in student engagement than males had while males had higher teacher self-efficacy in instructional strategies and classroom management. The study reported that gender influence teachers' self-efficacy with male and married teachers having higher self-efficacies.

\section{Concluding Remarks}

This study, therefore, concludes that male attempt to do more things in the school, put more effort in their work, persevere longer in their duties and recover faster when they fail to meet set targets. This is because Protheroe (2008) and Klassen and Chiu (2010) had found that teachers' self-efficacy determines levels of effectiveness, innovativeness and persistence among teachers. furthermore, teachers with high self-efficacy were found to be good in planning and organizing their work, more open to new ideas and innovative, more persistent and resilient (Prothroe, 2008). Therefore, male teachers who were found to have higher self-efficacies than females did in the current study might be expected to plan their work better, work harder and be more resilient than female teachers were.

\section{References}

Adu, E. O., Tadu, R. \& Eze, I. (2012). Teachers' self-efficacy as correlates of secondary school students' academic achievement in southwestern Nigeria. Discovery, 2012, 2(4), 8 - 16.

Akram, B. \& Ghazanfar, L. (2014). Self-efficacy and academic performance of the students of Gujarat University, Pakistan. Academic Research International, Vol. 5 No. 1: $283-290$. 
Aktaş, M., Kurt, H., Aksu, Ö. \& Ekic, G. (2013). Gender and experience as predictor of biology teachers' education process self-efficacy perception and perception of responsibility from student success. International Journal on New Trends in Education and Their Implications, Volume 4, Issue 3: 37 - 47.

Alberta Learning (2002). Health and Life Skills Guide to Implementation (K-9): Instructional Strategies. Retrieved on $6^{\text {th }}$ June 2015 from https://education.alberta.ca/media/352984/is.pdf

Al-Zu'bi, Z. H. (2013). Classroom management problems among teacher students training at Hashemite University. European Journal of Business and Social Sciences, Vol. 2, No. 3: $140-149$.

American Psychological Association (APA, 2011). The guidelines for psychological practice with lesbian, gay and bisexual clients. Retrieved on $24^{\text {th }}$ April 2014 from http://www.apa.org/pi/lgbt/resources/guidelines.aspx

Andersen, L. B. (2011). Teacher diversity: Do male and female teachers have different self-efficacy and job satisfaction? European Group for Public Administration (EGPA). Retrieved on 3rd February 2015 from https://soc.kuleuven.be/io/egpa/HRM/bucharest/ Andersen2011.pdf

Arslan, A. (2013). Investigation of Relationship between Sources of Self-efficacy Beliefs of Secondary School Students and Some Variables. Educational Sciences: Theory \& Practice - 13(4): 1983 - 1993.

Aslan, O. (2009). The Role of Gender and Language Learning Strategies in Learning English. Unpublished Thesis. Department of English Language Teaching, Middle East Technical University.

Aurah, C. \& McConnell, T. (2014). Comparative study on pre-service science teachers' self-efficacy beliefs of teaching in Kenya and the United States of America; USA. American Journal of Educational Research, 2014, Vol. 2, No. 4, pp. 233 - 239.

Bandura, A. (1967). Relative efficacy of self-monitored and externally imposed reinforcement systems. Journal of Personality and Social Psychology, Volume 7, Number 2: $111-116$

Bandura, A. (1989). Social cognitive theory. In R. Vasta (Ed.), Annals of child Development, Vol. 6. pp. 1 - 60. Greenwich, CT: JAI Press.

Bandura, A. (1989). Social cognitive theory. In R. Vasta (Ed.), Annals of Child Development, Volume 6: Six Theories of Child Development, pp. 1 - 60. Greenwich, CT: JAI Press.

Bandura, A. (1993). Perceived self-efficacy in cognitive development and functioning. Educational psychology, volume 28 (2): 117 - 148.

Bandura, A. (1994). Self-efficacy. In V. S. Ramachaudran (Ed.), Encyclopedia of Human Behavior, Volume 4, 71 - 81.

Bandura, A. (2001). Social Cognitive Theory: An Agentic Perspective. Annual Review of Psychology, Volume 52, 1 - 26.

Bandura, A. (2005). The evolution of social cognitive theory. In K. G. Smith and M. A. Hitt (Eds). Great Minds in management (pp. 9 35). Oxford: Oxford University Press.

Bilali, O. (2013). Teaching efficacy to student teachers in the faculty of education, Elbasan, Albania. Journal of Educational and Social Research, Volume $3(1)$, pp. $179-185$.

Braun, V. \& Clarke, V. (2006). Using thematic analysis in psychology. Qualitative Research in Psychology, Volume 3, Number 2: 77 101.

Boston University School of Public Health (BUSPH, 2013). The Social Cognitive Theory. Behavioral Change Models. Retrieved on 3rd January 2015 from http://sphweb.bumc.bu.edu/otlt/MPH-Modules/SB/SB721-Models/SB721-Models5.html

Butucha, K. (2013). Gender and school type differences in self-efficacy in teaching. Sky Journal of Educational Research Vol. 1(4): $23-$ 31.

Butucha, K. (2014). Relationships between secondary school beginning teachers' perceptions of self-efficacy and professional commitment in Ethiopia. International Journal of Academic Research in Progressive Education and Development, Vol. 3, No. 3 (Special Issue), pp. $79-104$.

Creswell, J. W. (2008). Research design: Qualitative, quantitative and mixed Methods approaches. Retrieved on May 7, 2014 from http://www.sagepub.com/upm-data/22780_Chapter_1.pdf

DeJaeghere, J. G., Williams, R. \& Kyeyune, R. (2009). Ügandan secondary school headteachers' efficacy: What kind of training for whom? International Journal of Educational Development, 29, pp. $312-320$.

Ferrara, M. M. (2013). Is gender a factor in classroom management: Looking from within a single-gender classroom? American Association of Colleges for Teacher Education, New York. Retrieved on $3^{\text {rd }}$ January 2015 from http://citation.allacademic. com/meta/p141507_index.html

Fielding, N. G. (2012). Triangulation and Mixed Methods Designs: Data Integration with New Research Technologies. Journal of Mixed Methods Research, Vol. 6, No. 2: $124-136$.

Gede, N. T. \& Lawanson, O. A. (2011). Employees' characteristics and job performance of staff of the Bayelsa State Ministry of Education. International Conference on Teaching, Learning and Change, pp. $558-565$.

Guion, L. A., Diehl, D. C. \& McDonald, D. (2011). Conducting an in-depth interview. FCS6012. Department of Family, Youth and Community Sciences, University of Florida.

Jumanne, J. (2012). Teacher self-efficacy in teaching science process skills: An experience of Biology teachers in Morogoro - Tanzania. Retrieved on 25 June 26, 2014 from www.amazon.com/Teacher-efficacy-teaching-science-process/dp/3659262129

Kinyua, M. \& Oboko, R. (2013). Impact of teacher's gender in imparting 21st competencies: Internal barriers in Kenya secondary schools. Research Project Report. School of Computing and Informatics, University of Nairobi.

Klassen, R. M. \& Chiu, M. M. (2010). Effects on teachers' self-efficacy and job satisfaction: Teacher gender, years of experience and job stress. Journal of Educational Psychology, 2010, Volume 102, Number 3: 741-756.

Mackay, J. \& Parkinson, J. (2010). Gender, self-efficacy and achievement among South African technology teacher trainees. Gender 
and Education, Volume 22, Issue 1: 87 - 103.

Martin, N. K., Yin, Z. \& Mayall, H. (2006). Classroom Management Training, teaching experience and gender: Do These Variables Impact Teachers' attitudes and beliefs toward classroom management style? Retrieved on April 22, 2015 from http://files.eric.ed. gov/fulltext/ED494050.pdf

McKenzie, L. \& Hannan, A. (2007). What are the advantages and disadvantages of interviews? Interviews in Education Research. Retrieved on 10 $10^{\text {th }}$ October, 2013 from www.edu.plymouth.ac.uk/resined/interviews/inthome.htm\#A. Introduction

Moalosi, W. T. S. (2012). Teacher Efficacy: Is Student Engagement Essential in Botswana Junior Secondary Schools? International Journal of Scientific Research in Education, 5(3), 207 - 213.

Mohammed, K. H., Atagana, H. I. \& Edawoke, Y. (2014). The difference between male and female students' self-efficacy, academic engagement and academic achievement in biology among grade ten students in South Wollo Zone schools in Ethiopia. Mediterranean Journal of Social Sciences, Vol 5 No 23: 804 - 813.

Moturi, E. S. (2014). The relationship between self -efficacy and academic performance in mathematics and English language among secondary school students in Nyamira District Kenya. Unpublished Dissertations. Moi University Repository.

Nakabugo, M. G., Opolot-Okurut, C., Masembe, C. S. , Mugimu, C. B., Ezat, B. \& Hurd, S. (2007). Large class teaching in Uganda: Implications for e-learning. Conference paper. Distance Education and Teacher Education in Africa.

Nanjala, M. (2012). Analysis of gender difference on entrepreneurial self-efficacy in Kenya: Case of small and medium entrepreneurs in Githurai trading centre, Nairobi. Institutional Repository. Kenyatta University.

Ngonyani, M. \& Werf, M. (2013). Teachers' Self-Efficacy and Attitudes towards Inclusive Education: A Survey of Primary School Teachers in Tanzania. Retrieved on $4^{\text {th }}$ January 2015 from http://www.amazon.com/Teachers-Self-Efficacy-Attitudes-InclusiveEducation/dp/3659307211

Obura, C. \& Ajowi, J. (2012). Students' perceptions of careers: the influence of academic performance and self-efficacy in Kisumu Municipality. Modern Social Science Journal, Volume 1, No. 1:56 - 93.

Odongo, G. (2011). Teacher perceptions of their readiness to educate children with sensory disabilities in Kisumu local education authority-Kenya: Bringing change that leads to new beginnings. Albuquerque: American Council on Rural Special Education (ACRES) Conference.

Oginga, E., Muola, J. \& Mwania, J. (2014). The factors influencing the teaching of HIV/AIDS education in public primary schools in Kisumu East district, Kenya. International Journal of Education and Research Vol. 2, No. 1: 1 - 14.

Okenyi, S. \& Enyi, G. S. (2015). Predictive value of gender on ego identity and achievement behaviour of schooling adolescents in Enugu State of Nigeria. International Journal of Education and Research, Vol. 3, No. 1: 271 - 282.

Oliver, R., Wehby, J. \& Daniel, J. (2011). Teacher classroom management practices: Effects on disruptive or aggressive student behavior. Campbell Systematic Reviews, Volume 4:1 -55.

Ongowo, R. \& Hungi, S. (2014). Motivational beliefs and self-regulation in Biology learning: Influence of ethnicity, gender and grade level in Kenya. Creative Education, Volume 5: 218 - 227.

Page, C. S., Pendergraft, B. \& Wilson, J. (2014). Examining elementary teachers' sense of efficacy in three settings in the Southeast. Journal of Inquiry \& Action in Education, Volume 5, Number 3: 31 - 41.

Protheroe, N. (2008). Teacher efficacy: What is it and does it matter? Principal: $42-45$.

Raburu, P. A. (2011). Women academics' careers in Kenya. Unpublished PhD Thesis. Lancaster University, UK.

Senemoglu, N., Demirel, M., Yagci, E. \& Ustundag, T. (2009). Elementary school teachers' self efficacy beliefs. Humanity and Social Sci. Journal 4 (2): $164-171$.

Taylor, S. E., Peplau, L. A. \& Sears, D. O. (2006). Social Psychology. Upper Saddle River: Pearson Education, Inc.

Teachers' Service Commission (2010). Teachers' Service Commission of Kenya Online Services: Listing of Schools - Kisumu County. Retrieved on May 18, 2014 from www.teachersonline.go.ke/masterbasic.aspx

Tenaw, Y. A. (2013). Relationship between self-efficacy, academic achievement and gender in analytical chemistry at Debre Markos College of teacher education. African Journal of Chemical Education (AJCE), 3(1): $3-28$.

Tison, E. B., Bateman, T. \& Culver, S. M. (2011). Examination of the gender-student engagement relationship at one university. Assessment \& Evaluation in Higher Education, Volume 36, Issue 1: 27 - 49.

Tschannen-Moran, M. \& Hoy, W. A. (2001). Teacher Efficacy Scales. Retrieved on 4th March 2014 from http://people.ehe.osu.edu/ahoy/ files/2009/02/tses.pdf

Turner, A. G. (2003). Sampling Frames and Master Samples. Retrieved on May 11, 2014 from http://unstats.un.org/unsd/demographic/ meetings/egm/sampling_1203/docs/no_3.pdf

Yeasmin, S. \& Rahman, K. F. (2012). Triangulation research method as the tool of social science research. Bangladesh University of Professionals (BUP) Journal, Volume 1, Issue 1, pp. $154-163$. 
